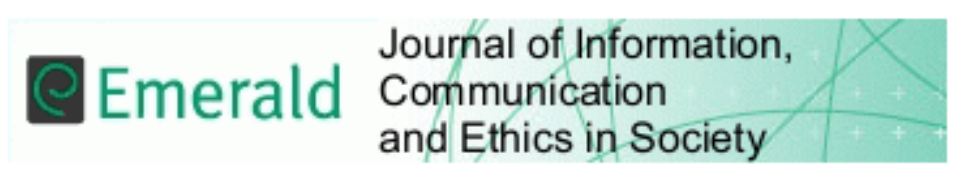

\title{
Artificial Intelligence Ethics Guidelines for Developers and Users: Clarifying their Content and Normative Implications
}

\begin{tabular}{|r|l|}
\hline Journal: & Journal of Information, Communication \& Ethics in Society \\
\hline Manuscript ID & JICES-12-2019-0138.R2 \\
\hline Manuscript Type: & Journal Paper \\
\hline Keywords: & $\begin{array}{l}\text { Artificial intelligence, AI ethics guidelines, recommendations for } \\
\text { emerging technologies, policy-making for disruptive technology, AI } \\
\text { principles }\end{array}$ \\
\hline
\end{tabular}

\section{SCHOLARONE \\ Manuscripts}




\title{
Artificial Intelligence Ethics Guidelines for Developers and Organisational Users - Clarifying the Content and Normative Implications of Ethical Principles
}

\begin{abstract}
There has been a significant amount of research done on the ethical consequences of artificial intelligence (AI). This is reflected by the works published across academia, policy and the media. Many of these aim to provide guidance to particular stakeholder groups. It has recently been shown that there is a large degree of convergence in terms of the principles upon which these guidelines are based. Despite this convergence, it is not always clear how these principles are to be translated into practice.

In this paper, we move beyond the high-level ethical principles that are common across the AI ethics guidance literature and provide a description of the normative content that is covered by these principles. The outcome is a comprehensive compilation of normative requirements arising from existing guidance documents. This is required for a deeper theoretical understanding of AI ethics, but also for the creation of practical and implementable guidance for developers and users of AI.
\end{abstract}

Keywords: artificial intelligence; AI ethics guidelines; recommendations for emerging technologies; policy-making for disruptive technologies

\section{Introduction}

Ethical consequences of artificial intelligence (AI) is a hot topic of debate across academia, policy and general media. It has been shown that there is a large degree of convergence in terms of the principles that guidance documents are based on (Jobin et al., 2019). At the same time, the principle-based approach adopted by much of the discourse has been criticised as insufficient in dealing with the practical issues raised by AI (Mittelstadt, 2019). The quicklygrowing set of tools that are being developed and provided to address AI ethics are often difficult to map with regards to the categories or principles they could help to address (Morley et al., 2019).

In this paper we move beyond the high-level ethical principles that are common across the AI ethics guidance literature and provide a description of the content that is covered by these principles. We build on Jobin et al's (2019, p. 395) robust categorisation of ethical principles. While their work provides a comprehensive overview of currently available AI ethics guidelines, their contribution is merely descriptive about these guidelines, rather than discussing the normative content of them. Our paper builds upon these foundations and uses their cohesive approach to develop a presentation of the normative content of these ethics guidelines for organisations developing and using AI. 
While there are an abundance of AI ethics guidelines, they remain separate and distinct from one another. As a consequence, it is difficult for individuals involved in the development or use of AI to determine which ethical issues they should be aware of, how these can present themselves and how they may be addressed. The reference to particular ethical principles, such as fairness, transparency or sustainability may be a good starting point, but further detail is required that allows AI organisations to think through the implications of these principles for their work.

A further issue of AI ethics guidelines is that they are aimed at a range of stakeholders: policymakers, users, developers, but also educators, civil society organisations, industry associations, professional bodies and more. As a consequence, the guidelines that are currently available are often difficult to understand and are written for technical users who constitute one key user group.

In this paper we therefore provide a detailed explanation of the normative implications of existing AI ethics guidelines, but directed towards developers and organisational users of AI. ${ }^{1}$ We believe that the paper provides the most comprehensive account of ethical requirements in AI guidelines currently available, which is of interest to the research and policy community engaged in the topic but also to the user communities that require guidance when developing or deploying AI systems. It must be made clear here that we are not providing prescriptive recommendations, but rather, are mapping the prescriptive recommendations found in these guidelines.

In order to provide this normative account, we start with a brief overview of the current academic and policy-oriented discourse on ethics and AI. We then describe the methodology of our work and how we compiled the relevant insights. The largest section of the paper describes 11 normative principles (transparency, justice \& fairness, non-maleficence, responsibility, privacy, beneficence, freedom \& autonomy, trust, sustainability, dignity, and solidarity) and the various subcategories of these principles. In conclusion, we highlight the contribution of this work and suggest next steps.

\section{Research and Policy in Ethics and AI}

Ethics guidelines constitute one aspect of the larger academic and policy discourse around ethics and AI. It is probably not contentious to state that an interest in ethics and AI is now a global phenomenon. The amount of attention currently paid to the topic is impressive and the literature has mushroomed to the point where it is difficult to keep on top of it. In this paper we focus on ethics guidelines, but these need to be seen as one aspect of a broader literature on ethics and AI.

Ethics of AI is not a new topic. What falls under this heading depends on the definition of the term AI. A typical definition is: "we define AI as a system's ability to interpret external data correctly, to learn from such data, and to use those learnings to achieve specific goals and tasks through flexible adaptation" (Kaplan and Haenlein, 2019, p. 17). Aspects that are typically

\footnotetext{
1 Throughout the paper, we will simply refer to developers and users of AI systems as "AI organisations" for convenience's sake.
} 
described as defining features of AI that can give rise to ethical concerns are the ability to learn and to act more or less autonomously on the basis of external input and adaptation.

If these characteristics are at the core of the ethical discussion of AI, then they can be traced back to the very beginning of discussions of ethics and digital technology in the 1940s and 50s (Wiener, 1954) and they have been driving at least parts of the debate on ethics and technology, computing and information ever since (Bynum, 2010; Bynum and Rogerson, 2003; Capurro, 2006; Moor, 1985). However, even though the debate can be followed back several decades, it has become invigorated in recent years. The generally accepted explanation for this upsurge in AI ethics is based on recent successes and achievements of some AI techniques, and their widespread application in domains such as smart cities (Ryan and Gregory 2019; Ryan 2019b), agriculture (Ryan 2019a), and transportation (Ryan 2019c).

In particular, machine learning and deep neural networks have been hugely successful in recent years. While not a fundamentally novel technology, recent successes of machine learning have been made possible by the availability of large data sets for training and testing purposes and the affordability and availability of large amounts of computing power. It is important to note that the field of AI, which has been a long-standing part of computer science, goes beyond machine learning, big data and neural networks, but these are at the heart of the current debate. A typical description of the expectation of AI's future role is: "[...] AI will become as much a part of everyday life as the Internet or social media did in the past. In doing so, AI will not only impact our personal lives but also fundamentally transform how firms take decisions and interact with their external stakeholders (e.g., employees, customers)" (Haenlein and Kaplan, 2019, p. 9).

This widely shared and accepted narrative that AI will have a large impact on many aspects of life explains the high level of public interest. There have been numerous high-level policy reports that describe the current and expected effects of AI on society and economy (Executive Office of the President, 2016a, 2016b; HoL, 2018; House of Commons Science and Technology Committee, 2016; OECD, 2019). Many industrialised countries now have AI strategies and government departments (Stix, 2019). This policy-oriented discussion reflects the academic research discourse around AI ethics (Berendt, 2019; Clarke, 2019; Floridi, 2019; Johnson et al., 2019; Morley et al., 2019) but looks at it from a policy perspective. Their proposals range from national or international regulation and legislation and the corresponding creation of regulatory bodies to corporate governance mechanisms, the creation of standards and codes of ethics to a range of sector-specific measures (e.g. in health, automation, military) and technical means.

Many of the outputs of research-oriented, private and political organisations on AI ethics take the form of guidelines. Prominent examples include the EU's high level expert group on AI's guidelines (HLEG, 2019) or the Asilomar AI principles (Asilomar Conference, 2017). These guidelines aim to provide guidance for particular stakeholder groups on how to deal with ethical issues they face. They often contain a set of ethical principles which are then used to deduce more specific guidance. Such guidelines need to be read in the context of the legal structure in which they apply. While ethics guidelines often aspire to be incorporated within policy frameworks, they are in themselves meant as guiding frameworks, rather than indicating or enforcing legal parameters for action. Thus, the guidelines are intended as indications towards ethical behaviour, but their target audiences should abide by current legislation in the area and not negate their legal obligations. 
The question that motivated this paper was which practical guidance is available to people who develop or use AI that will help them address ethical concerns they face. Our starting assumption was that the answer to this question should be found in AI ethics guidelines. However, the wealth of existing guidelines raises two related problems that this paper aims to address. One problem is that many of the guidelines are very broad in terms of coverage, i.e. they provide guidance for many different stakeholder groups, including policymakers, companies, users, civil society representatives etc. Secondly, there is now such a wealth of guidelines that it is very difficult to navigate and understand which pieces of guidance exist and what the specific guidance is.

This paper is aimed particularly at people who develop or use AI systems and it tries to clarify which ethical principles can guide their work. Most importantly, the paper drills down more deeply into the details of the body of knowledge and specifies which ethical aspects are covered by the range of principles and what users and developers should do to carry out their moral responsibilities. We have compiled the most comprehensive document collecting existing guidance which can guide practical action, but will hopefully also support the consolidation of the guidelines landscape. Our findings should also be of academic interest and inspire philosophical research on the consistency and justification of the various normative statements that can be found in the literature.

Before we come to the actual guidance, we give a quick overview of the methodology employed in our research.

\section{Methodology}

The most important requirement for our research was to have a comprehensive dataset of AI ethics guidelines. In order to achieve this, we started with a structured search of available databases (Scopus, Web of Science, Google Scholar), using the search terms including "AI ethics", "AI guidelines". We compared our findings with existing collection of relevant documents, notably Stix's European AI Ecosystem (https://www.charlottestix.com/europeanunion-ai-ecosystem), the Algorithmwatch AI Ethics Guidelines Global Inventory (https://algorithmwatch.org/en/project/ai-ethics-guidelines-global-inventory/) but also broader AI repositories, such as the Open AI website (https://openai.com/). We collected all the documents that were publicly available and then broadened our search on the basis of references in the published literature as well as references in the guidelines we had already secured.

We used the most comprehensive and rigorously structured overview of guidelines published so far (Jobin et al., 2019) to validate our data set. The result was that we analysed Jobin's 82 sets of ethical guidelines and an additional 9 guidelines (see articles in bold in appendix 1) that they did not include (the total was 91 guidelines). ${ }^{2}$

We then undertook a thematic analysis of all the guidelines (Aronson, 1995; Braun and Clarke, 2006). As a starting point we used the ethical principles that are used by the EU's HLEG (2019) as high level coding points. We then identified which ethical principles or guidance fell

\footnotetext{
2 The additional 9 guidelines were: ADMA 2013; Algo.Rules 2019; B Debate 2017; Council of Europe 2017; IPC Ontario 2017; OECD 2019; Personal Data Protection Commission Singapore 2019; UK Government, Department for Digital, Culture, Media \& Sport 2018; and UNDG 2017.
} 
underneath each of these headings. Table 1 (below) provides an overview of the main principles and the ethical issues that constitute these.

\begin{tabular}{|c|c|c|c|c|}
\hline Principle & \multicolumn{4}{|c|}{ Constituent ethical issues or guidance } \\
\hline Transparency & transparency & explainability & $\begin{array}{l}\text { explicabilit } \\
\text { y }\end{array}$ & understandability \\
\hline & interpretability & communication & disclosure & showing \\
\hline \multirow[t]{4}{*}{$\begin{array}{l}\text { Justice and } \\
\text { fairness }\end{array}$} & justice & fairness & consistency & inclusion \\
\hline & equality & equity & non-bias & $\begin{array}{l}\text { non- } \\
\text { discrimination }\end{array}$ \\
\hline & diversity & plurality & $\begin{array}{l}\text { accessibilit } \\
\text { y }\end{array}$ & reversibility \\
\hline & remedy & redress & challenge & $\begin{array}{ll}\text { access } & \text { and } \\
\text { distribution } & \end{array}$ \\
\hline \multirow[t]{3}{*}{ Non-maleficence } & non-maleficence & security & safety & harm \\
\hline & protection & precaution & prevention & integrity \\
\hline & non-subversion & & & \\
\hline Responsibility & responsibility & accountability & liability & $\begin{array}{l}\text { acting with } \\
\text { integrity }\end{array}$ \\
\hline Privacy & privacy & $\begin{array}{l}\text { personal or } \\
\text { private } \\
\text { information }\end{array}$ & & \\
\hline \multirow[t]{2}{*}{ Beneficence } & benefits & beneficence & well-being & peace \\
\hline & social good & common good & & \\
\hline \multirow{2}{*}{$\begin{array}{l}\text { Freedom and } \\
\text { autonomy }\end{array}$} & freedom & autonomy & consent & choice \\
\hline & self-determination & liberty & $\begin{array}{l}\text { empowerm } \\
\text { ent }\end{array}$ & \\
\hline Trust & trustworthiness & & & \\
\hline Sustainability & sustainability & $\begin{array}{l}\text { environment } \\
\text { (nature) }\end{array}$ & energy & $\begin{array}{l}\text { resources } \\
\text { (energy) }\end{array}$ \\
\hline Dignity & dignity & & & \\
\hline
\end{tabular}




\section{Guidelines for the Development and Use of AI}

Following this methodology, we analysed the set of guidelines and compiled the detailed guidance that is available to developers and users. We established that while there was a strong degree of overlap about the main issues and themes within the guidelines, they often differed in a number of areas: emphasis on the topic (a greater emphasis on algorithms, privacy and security, or safety), the tone (varying between dogmatic 'must do' principles to more open 'if possible' recommendations), length (ranging from 1 page to over 266 pages), level of technicality (very technical to layman terminology), and audience (end-users, developers, companies, policymakers, or society as a whole).

The following subsections highlight the nature of the ethical issues and guidance that has been suggested for developers and users to follow. We reference the relevant guidelines where required, but should state that we only provide minimal references per section because our aim is to give an overview of the ethical aspects and the normative content within all of these guidelines, rather than providing a systematic and robust mapping of guidelines to issues, as this has already been done quite well in Jobin et. al (2019).

\section{Transparency}

Transparency has quickly become one of the most widely discussed principles within the AI ethics debate, with Floridi (2019) and the High-level Expert Group (2019) viewing it as a defining characteristic within the debate. Transparency can typically be understood in two ways: the transparency of the AI technology itself and the transparency of the AI organisations developing and using it. Throughout our analysis, transparency was regularly discussed directly, or in relation to processes required to ensure it, such as explainability, understandability, and communication. 


\section{a. Transparency}

AI developers need to ensure transparency because it protects many other requirements - such as the fundamental human rights, privacy, dignity, autonomy, and well-being (UNI Global Union 2017). Organisations using AI should be transparent about their aim for using AI, benefits and harms, and potential outcomes that may occur (IBM 2017). AI developers should ensure transparency because it allows consumers to make informed choices about sharing their data and using AI (ADMA 2013).

\section{b. Explainability}

AI must be subject to active monitoring to ensure that they are producing accurate results (Algo.Rules 2019). AI organisations should document how their AI makes certain decisions and be able to reproduce them for audits (SIIA 2017). AI should be explainable to external algorithmic auditing bodies to ensure the technical and ethical functionality of their AI. If there is a tension between performance and explainability, this should be clearly identified (CERNA 2018).

\section{c. Explicability}

AI organisations (i.e. organisations using or developing AI) should be able to intelligibly explain the data that goes in, the data coming out, what their algorithms do, and their objective for doing so (Demiaux \& Abdallah 2017, p. 51). AI organisations should ensure traceability and explicability to guarantee safety (OECD 2019). AI needs to have a strong degree of traceability to ensure that if harms arise, they can be traced back to the cause (IEEE 2017). Data should be traceable back to where, how, and when it was captured, retrieved, cleaned, and analysed (CERNA 2018). Decisions made by AI should be reproducible by external auditors (AMA 2018).

\section{d. Understandability}

AI organisations need to implement appropriate methods to monitor the data, algorithms, and the decisions that will be arrived at by those processes, and for actions taken by AI to be comprehensible by human beings (European Parliament 2017). AI organisations should understand how their AI works and explain the technical functioning and decisions reached by those technologies, whenever possible (Floridi et. al 2018).

\section{e. Interpretability}

While there is a degree of opaqueness in some machine-learning technologies, AI organisations should be able to understand how a decision was reached and how human oversight ensures that harms caused by algorithmic black-boxing are addressed and prevented (IEEE 2019). High-stake domains (such as healthcare, criminal justice and welfare) should reconsider using black-box AI altogether (AI Now Institute 2017). Algorithmic reviews should be done on a regular basis to determine if they are fit-for-purpose and interpretable (Algo.Rules 2019). Organisations should be able to clearly interpret and demonstrate how their AI is abiding by current legislation, such as the GDPR, and be able to demonstrate what measures are being taken to ensure compliance (UK Government 2018). 


\section{f. Communication}

End-users should be provided with accurate information to ensure that they are not manipulated, deceived, or coerced by AI (HLEG 2019, p. 16). End-users should be informed about the intent and outcomes of the technology (IBM 2018). AI companies should be explicitly clear, and discuss in a jargon-free manner, the potential flaws or harm that may arise from their AI (Algo.Rules 2019). Communication methods may have to change for different industries, expertise, and context of use (Floridi et. al 2018). AI organisations should communicate their progress and likelihood to hit particular milestones to governments, so that they can plan for these outcomes (NSTC 2016a).

\section{g. Disclosure}

AI should be designed and used to retrieve little to no personal data, or if required, that any data retrieved is anonymised, encrypted, and securely processed; while being able to demonstrate this to a third-party auditor (HLEG 2019). AI should go through internal and external auditing to ensure they are fit for purpose, but the organisation also needs to be able to explain and justify the use of their AI. Organisations should allow for independent analysis and review of their systems (Amnesty International 2018).

\section{h. Showing}

Data should be accurate, up-to-date, and fit-for-purpose, and companies should be able to demonstrate this (ICO 2017). Data quality should be transparent, available for periodic assessment, and there should be regular and continued anomaly-detection set in place (UNDG 2017). Developers of AI should also be able to provide their ethics codes to public authorities, organisational users, and where possible, the public (Université de Montréal 2017). This can be achieved through periodic review sessions, appropriate oversight mechanisms, and collective responsibility approaches within the organisation (ICDPPC 2018). It should also be clear to the end-user that they are interacting with an AI system, rather than a human (EPSRC 2011).

\section{Justice and Fairness}

Discrimination and unfair outcomes stemming from algorithms has become a hot-topic within the media and academic circles (O'Neil 2016). It is not surprising that issues of fairness, equality and equity were repeatedly discussed throughout the ethics guidelines. In addition to simply addressing issues of harm and injustice themselves, many of the guidelines provided recommendations on how to implement steps to minimise these harms. Furthermore, some documents also highlighted how different organisations should implement methods to reverse, remedy, and allow fair redress, in instances where harms have occurred.

\section{a. Justice}

AI practitioners should identify what levels of justice and fairness can be implemented into the AI system during the design process (NSTC 2016b). For example, if AI is used within the judicial system in any way, accountability should still lie with the human user, e.g. the judge (Rathenau Institute 2017, p. 43). In addition, AI will replace many human jobs in the future, so 
it is important that there are effective and just ways to retrain and retool the human workforce (COMEST/UNESCO 2017, p. 52-53).

\section{b. Fairness}

While AI developers may have their own values, they should not develop algorithms with historically unfair prejudices (Latonero 2018). There should be steps in place to ensure that data being used by $\mathrm{AI}$ is not unfair, or contains errors and inaccuracies, that will corrupt the response and decisions taken by the AI (ICO 2017). In order to ensure the fairness of AI, their design should be fit for purpose; identify impacts on different aspects of society; and should be designed to promote human welfare, rather than endanger it (ICDPPC 2018). Organisations should consider using fairness-aware data mining algorithms (FATML 2016).

\section{c. Consistency}

In order to prevent harmful actions in the decision-making process, organisations should ensure that accurate and representative sample data is collected, analysed, and used (IPC Ontario 2017). Organisations need to establish procedures to ensure the identification, prevention, and the minimisation of inaccuracies in their AI. In order to achieve this, data should be of the highest quality (UNDG 2017); external algorithmic auditing should be carried out (Intel 2017); and there should be consistent, repeated, and regular discussions with end-users and stakeholders that may be affected (PwC 2019).

\section{d. Inclusion}

AI should not become another tool for exclusion within society (AI for Humanity 2018). Particular attention should be given to under-represented and vulnerable groups and communities, such as those with disabilities, ethnic minorities, children, and those in the developing world (HLEG 2019). Data that is being used should be representative of the target population and should be as inclusive as possible (HLEG 2019). AI organisations should not only reduce exclusion issues, but should promote active inclusion of women and minority groups into the development and design of AI (Gilburt 2019; WEF 2018).

\section{e. Equality}

AI should not harm, and where possible, should promote, the equality of individuals in respect to their rights, dignity, and freedom to flourish (The Future Society 2018; Tieto 2018). One way equality can be enabled is through greater diversity in AI teams, and data sets and designs (Sage 2017). More steps need to be taken to address sexist, misogynistic, and gender-biased harms resulting from some AI (World Wide Web Foundation 2018).

\section{f. Equity}

The aims of AI, generally, should be to empower and benefit individuals, provide equal opportunities, while distributing the rewards from its use in a fair and equitable manner (EGE 2018; IEEE 2019; SIIA 2017). AI should be developed so that it can be used within society in a fair and equal way (Japanese Society for Artificial Intelligence 2017). 


\section{g. Non-bias}

AI organisations should invest in ways to identify, address and mitigate unfair biases (ICDPPC 2018). Developers should examine unfair biases at every stage of the development process and should eliminate those found (The Public Voice 2018). There should be close attention paid to the training data used; potential human biases; and bias derived from the results of algorithmic processes (CERNA 2018). Developers and organisational users of AI should conduct analysis to identify unfair bias; and there should be explicit attempts to avoid individual and societal bias; continual mechanisms in place, and dialogue with stakeholders, to raise awareness and reverse any biases detected (IBM 2018). If there is any indication of unfair bias, the AI organisations should demonstrate the elimination of such bias before a competent authority (Council of Europe 2017).

\section{h. Non-discrimination}

AI should be designed for universal usage and not discriminate against people, or groups of people, based on gender, race, culture, religion, age, or ethnicity (CERNA 2018). There should be mechanisms in place to effectively prevent, remedy, and reverse discriminatory outcomes resulting from AI use (Amnesty International 2018). AI use should not lead to discrimination against individuals or groups of individuals in accordance with the Equality Act 2010, and organisations should create 'discrimination impact assessments' to identify issues before their AI are used (AI for Humanity 2018).

\section{i. Diversity}

In order to promote diversity, AI organisations should instil an inclusionary working environment (CERNA 2018), hire teams from a range of backgrounds (IBM 2018) and disciplines (SAP 2018), conduct regular diversity sessions, and incorporate the viewpoints from a wide range of stakeholders (Amnesty International 2018). Organisations implementing and using AI should encourage a diversity of opinions throughout every stage of its use (Smart Dubai 2019).

\section{j. Plurality}

AI developers should consider the range of social and cultural viewpoints within society and should attempt to prevent societal homogenization of behaviour and practices (Université de Montréal 2017). Organisations should not only be focused on 'pipeline model' changes in their organisation, but should ensure that the plurality of individuals within their organisation have a voice and they create a culture of inclusion, which should be reflected in the AI technology (AI Now Institute 2018). Create a multi-stakeholder dialogue and incorporate the viewpoints of women, underrepresented groups and marginalised individuals at every stage of AI applications (Leaders of the G7 2018).

\section{k. Accessibility}

Organisations should protect the rights of data subjects, such as the right of information access about them (Datatilsynet 2018). Individuals have a right to access data that is being stored and used about them, and subsequently, to request that this is rectified or deleted (Datatilsynet 2018). When decisions are made about individuals, explanations should be available that are easily accessed, free of charge and user-friendly (Smart Dubai 2019). 


\section{Reversibility}

It is important to clearly articulate if the outcomes of AI decisions are reversible, e.g. if individuals are refused a loan because of an AI algorithm, can such a decision be reversed if the customer can demonstrate their credit-worthiness (Personal Data Protection Commission Singapore 2019, p. 16). Organisations using AI need to ensure that the autonomy of AI is restricted and the outcomes are reversible when there is a harm caused (Floridi et. al 2018). AI should be programmed with a condition of reversibility, which ensures controllability and safety of the system: 'The ability to undo the last action or a sequence of actions allows users to undo undesired actions and get back to the 'good' stage of their work' (Clarke 2019).

\section{m. Remedy}

When AI holds the possibility of creating harm, there needs to be preemptive steps in place to trace these issues and deal with them in a prompt and responsible manner. Organisations should abide by the 'termination obligation', which states that when a system is no longer under human control, then it must be terminated (Telefónica 2018). There needs to be specific 'red lines' drawn, that when breached, appropriate steps are taken to override the system, terminate it temporarily or indefinitely, and remedy any potential issues that may have occurred $(\mathrm{PwC}$ 2019).

\section{n. Redress}

In situations where harmful and/or unjust events occur as a result of using AI, those affected should have appropriate and visible measures of redress in a timely manner (FATML 2016). When decisions made by algorithms create harmful or questionable results, individuals should have the possibility to lodge a complaint and request a justification of the decision (Algo.Rules 2019). This should be done in a manner that is understandable by those affected and should allow them the opportunity to challenge these decisions (B Debate 2017). Accountability strategies should be created within companies, with appropriate measures for redress if these internal and external standards are not met (Dawson et al. 2019).

\section{o. Challenge}

AI companies should allow for 'conscientious objectors, employee organizing, and ethical whistleblowers' (AI Now Institute 2018). There should be clear policies to protect conscientious objectors, employees to voice their concerns, and whistle-blowers to feel protected, when it is in the public interest and safety (AI Now Institute 2018).

\section{p. Access and Distribution}

AI organisations should ensure that their technologies are fair and accessible among a diversity of user groups within society (Smart Dubai 2019). Organisations should especially concentrate on 'populations that currently lack such access' (AI Now Institute 2016, p. 3). AI should be accessible to those that are often socially disadvantaged (such as those with vision problems, dyslexia, or mobility issues) (Sage 2017). Wherever possible, organisations should use open data for their AI to ensure access and transparency (NSTC 2016b). 


\section{Non-maleficence}

The principle of nonmaleficence gained attention, resulting from Beauchamp and Childress (1979) ground-breaking Principles of Biomedical Ethics, and its subsequent editions. In its most basic form, it means to do no harm, or avoid doing harm to others. In AI ethics, the avoidance of harm to human beings has been one of the greatest concerns, with some of the most high-profile examples coming from killer robots, autonomous cars, and drone technology. It is no surprise that most of the ethics guidelines had a strong emphasis on ensuring no harm comes to citizens, through security and safety of the AI, and precautionary and remedial steps to be taken, if harm occurs.

\section{a. Non-maleficence}

AI should be designed with the intent of not doing foreseeable harm to human beings (Personal Data Protection Commission Singapore 2018). Developers and organisations using AI should receive, and incorporate the advice of legal authorities and research ethics boards (REB) to ensure that data is retrieved, analysed, and used in a manner that does not harm individuals (IPC Ontario 2017). Organisations should regularly test their algorithms to determine that no harm results from them (ACM 2017; American College of Radiology 2019).

\section{b. Security}

AI should be robust, secure and safe throughout their lifecycle and must function appropriately and not pose unreasonable safety risks (OECD 2019). Organisations must ensure effective cybersecurity so that their AI is protected against attacks (Allistene 2014). Security must be built into the architecture of the AI (Public Voice 2018) and must be tested before implementation (Algo.Rules 2019). When security researchers find vulnerabilities or design flaws, they should disclose these findings to be resolved (Internet Society 2017).

\section{c. Safety}

Developers and organisational users should ensure that AI does not infringe on human rights by ensuring their technology's safety (EGE 2018). They must assess the public safety risks that arise from their AI and implement effective safety controls (Public Voice 2018). Organisations should enforce strict safety measures, ensuring their AI's manageability and control, and that adequate procedures are in place for security breaches (Algo.Rules 2019). AI should pass quality assurance processes and be tested in real-world scenarios before, during, and after deployment (SAP 2018).

\section{d. Harm}

The objectives and expected impact of AI must be assessed and documented in the development stage (Algo.Rules 2019). The effects of these systems must be reviewed on an ongoing basis (Algo.Rules 2019). Organisations should encourage a form of 'algorithmic accountability' and should exercise caution when developing AI that may have negative impacts (ICO 2017). AI technology that replaces human activity should produce at least a diminution of harm before it is allowed on the market (Federal Ministry of Transport and Digital Infrastructure 2017). AI should not 'cause bodily injury or severe emotional distress to any person' (IIIM 2015). 


\section{e. Protection}

Developers should implement mechanisms and safeguards to protect user safety (OECD 2019), and AI must be safe and secure throughout their lifecycle (IEEE 2019). AI systems should prioritize the protection of human life (Federal Ministry of Transport and Digital Infrastructure 2017). External auditors should be allowed to conduct examinations and report negative impacts of the AI without fear of harm or threat by the AI organisations. In addition, the protection of whistle-blowers within AI organisations should also be ensured to allow for effective and legitimate reporting of harms (HLEG 2019, p. 20).

\section{f. Precaution}

Those who develop AI must have the necessary skills to understand how they function and their potential impacts (Algo.Rules 2019), and security precautions must be well documented (Public Voice 2018). AI organisations may receive advice from trained legal professionals, ethicists working in the area, and policy analysts. If no consensus can be agreed upon, development of the AI 'should not proceed in that form' (HLEG 2019, p. 20). AI systems need to allow for human interruption, or their shutdown, when there is potential harm (Internet Society 2017).

\section{g. Prevention}

An AI system must be manageable throughout the lifetime and its control must be made possible (Algo.Rules 2019). The reliability and robustness of AI and its reliability with respect to attacks, access and manipulation must be guaranteed (Public Voice 2018). Great effort should be put into ensuring reliability and safety (IEEE 2019). AI systems should prevent accidents from occurring, whenever possible, and avoid critical situations from occurring in the first place (Federal Ministry of Transport and Digital Infrastructure 2017).

\section{h. Integrity}

Attacks against AI should not compromise the bodily and mental integrity of people by ensuring the reliability and internal robustness of the systems (EGE 2018). AI should "fail gracefully" (e.g., shutdown safely or go into safe mode) (IEEE 2019).

\section{i. Non-subversion}

AI systems should be used to respect and improve the lives of citizens, rather than 'subvert, the social and civic processes on which the health of society depends' (Future of Life 2017).

\section{Responsibility}

Moral responsibility is a very important issue within AI ethics, with a fear that companies will try to obfuscate blame and responsibility onto the autonomous or semi-autonomous system. There may also be incidences where because of this relative autonomy, AI creates a 'responsibility gap', whereby it is unclear who is responsible. Issues of responsibility, accountability, liability, and acting with integrity appeared in many of the ethics guidelines that we analysed. 


\section{a. Responsibility}

Developers are primarily responsible for the design and functionality of the AI, and when there is an error or harm, then the onus of responsibility often lies with them. When the issue is caused by the use and implementation of the technology, the onus is with the organisational user of the AI. There needs to be clear and concise allocation of responsibilities within the organisation using AI, and the creation of potential scenarios and ways to deal with harms when they occur (EGE 2018; FATML 2016).

\section{b. Accountability}

AI organisations need to be aware of the issues involved with using poor data, and be held accountable if there are harmful consequences as a result of this. Developers need to be aware that they are accountable for these systems' impact on the world (IBM 2018). They need to be open and accountable by means of auditing, monitoring, and conducting impact assessments of AI (ICDPPC 2018). A legal person must always be held accountable for harms caused by $\mathrm{AI}$ and this blame cannot be placed on the tools that cause the damage (Algo.Rules 2019).

\section{c. Liability}

There is a need to distinguish between the designer and organisational users of those systems for legal reasons (CERNA 2018). In order to attribute liability in situations of malfunction, error, and harms, there needs to be clear attributions of responsibility. Definitive liability should be established for when autonomous systems cause undesired effects (EGE 2018). This can be achieved through adequate record-keeping, systems for registration, and documentation (IEEE 2019).

\section{d. Acting with Integrity}

AI organisations must ensure that their data meets quality and integrity standards at every stage of use (ITI 2017). If those working with AI discover errors, security breaches or data leaks, then they must report these issues to the relevant authorities, stakeholders, and if relevant, the wider public (Université de Montréal 2017). Ethics training should be implemented to ensure responsible development and deployment of AI (AI for Humanity 2018). AI companies should respect and support the academic and professional integrity of their partners and researchers (Deepmind 2017).

\section{Privacy}

Since the GDPR came into force in 2018, privacy has been a hot-topic for anyone working in fields where personal data is being used. Particularly, there is a great concern in the development and use of AI, with many of the ethics guidelines strongly featuring privacy and data protection as key tenets in their recommendations. Because of the large abundance of data that is required for AI to work, it is important that individuals' privacy is not jeopardised as a result. 


\section{a. Privacy}

Some of the steps that AI organisations should take to ensure privacy are: the security of databases, storage, and AI systems through de-identification, anomaly-detection, and effective cybersecurity (IPC of Ontario 2017); ensuring informed consent is retrieved (EGE 2018); users should have control and access to data stored about them (IEEE 2019); follow current data protection regulations (UK Government 2018) and non-regulatory privacy-by-design frameworks (ICDPPC 2018); and ensuring that the data retrieved is of a high standard. Organisations purchasing off-the-shelf AI can cultivate a privacy culture by demanding privacy-by-design AI (Datatilsynet 2018).

\section{b. Personal or Private Information}

The development and use of AI should ensure a strong adherence to the privacy and data protection standards outlined in the GDPR (2018), in addition to non-regulatory frameworks, such as privacy-by-design and privacy impact assessment frameworks (IEEE 2019; Intel 2018). Developers and organisational users of AI must place the end-user's privacy and personal data at the forefront of the design process; viewing privacy as a human right (Latonero 2018). The end-user's personal data, and data derived or created about them, should be processed in a fair, lawful, and legitimate way (UNDG 2017). Whenever possible, the collection and use of personal data should be kept to a minimum, unless completely necessary and relevant (Datatilsynet 2018).

\section{Beneficence}

The principle of beneficence also gained greater acknowledgement and adoption after Beauchamp and Childress (1979) Principles of Biomedical Ethics. Beneficence essentially means to do good, to carry out an activity with the intention of benefitting someone or society as a whole. Often, beneficence is overlooked in the AI ethics literature, often being seen as a given that AI will bring benefits. The ethics guidelines we analysed highlighted beneficence to promote the flourishing of individual well-being, ensuring people receive benefits from AI use, or that it should promote peace and the social and common good.

\section{a. Benefits}

AI organisations should ensure that their AI is designed to benefit humans (IEEE 2019). They should clearly map out those benefits and the parties benefiting from them (The Information Accountability Foundation 2015). AI systems must create greater benefits than their costs for people (Dawson et al. 2019, p. 6) and should benefit as many people as possible (Future of Life Institute 2017; The Partnership on AI 2016). AI organisations should 'advance scientific understanding of the world, and to enable the application of this knowledge for the benefit and betterment of humankind' (IIIM 2015).

\section{b. Beneficence}

AI organisations should find solutions to some of the world's greatest problems, such as curing diseases, ensuring food security, and preventing environmental damage (Intel 2017). AI organisations should use data retrieved for the benefit of their customers and society (OP 2019). Ultimately, AI should 'compliment the human experience in a positive way' (Unity Blog 2018). 


\section{c. Well-being}

AI organisations should ensure individual well-being and flourishing (IEEE 2019). They should ensure that their AI is fit-for-purpose and that it does not prohibit individual development and access to primary goods, it ensures human welfare, and allows for the empowerment of individuals around the world (EGE 2018). AI should be used to compliment those working in the healthcare sector to provide better care and support the wellbeing of patients (RCP London 2018).

\section{d. Peace}

AI organisations should aim to avoid an 'arms race in lethal autonomous weapons' (Future of Life Institute 2017; see also Smart Dubai 2019). If AI threatens peace, organisations should collaborate with governments to reduce potential conflicts (OpenAI 2018).

\section{e. Social Good}

AI should bring an improvement in beneficial opportunities for society (The Information Accountability Foundation 2015, p. 10). AI organisations should cultivate a healthy AI industry ecosystem, built on cooperation and healthy competition (Government of the Republic of Korea 2017, p. 62). The use of AI should not come at a cost of causing a conflict with nonusers of these technologies (Ministry of State for Science and Technology Policy 2019, p. 22).

\section{f. Common Good}

AI should be developed to support the common good (Future of Life 2017) and the service of people (AGID 2018). AI organisations should weigh up the benefits and harms resulting from $\mathrm{AI}$ and should take careful consideration to develop ways to mitigate and harms to ensure an overall common good for society (The Information Accountability Foundation 2015, p. 8). Appropriate steps should be considered to ensure that AI is used for good and that humanity is protected from potentially harmful impacts resulting from it (OpenAI 2018).

\section{Freedom and Autonomy}

Democratic societies place value in freedom and autonomy, and it is important that AI use does not encumber or harm these for us. The ethics guidelines addressed ways to ensure autonomypromoting and liberty-protecting AI. For example, the AI organisation should ensure that individuals consent to how their data is being used, AI should not harm individuals' abilities to make choices, or manipulate their self-determination.

\section{a. Freedom}

Developers should acknowledge, identify, and ameliorate circumstances where AI may create harm against human freedoms. Organisations should ensure that the end-users' freedoms are not infringed upon during the use of AI (HLEG 2019). Developers should ensure that AI does not harm end-users through tracking (freedom of movement), censorship (freedom of expression), or surveillance (freedom of association). 


\section{b. Autonomy}

AI organisations should ensure that end-users are informed, not deceived or manipulated by AI and should be allowed to exercise their autonomy (EGE 2018). AI organisations need to ensure that the 'principle of user autonomy must be central to the system's functionality' (HLEG 2019, p. 16). Users should be informed actors and have control over their decisions when interacting with AI (Council of Europe 2019).

\section{c. Consent}

The use of personal data must be clearly articulated and agreed upon before its use (UNDG 2017). If personal data is repurposed, developers should ensure that it is compatible with the original fair processing requirements when consent is given (ICO 2017), in those cases where consent is the legal basis of data processing. Personal data should not be processed in a way that the data subject considers inappropriate or objectionable (Council of Europe 2017). The use of personal data should also be done within reasonable expectations and consent of the individuals but must also be used for legitimate purposes (Future Advocacy 2019).

\section{d. Choice}

AI should protect users' power to decide about decisions in their lives (Floridi et. al 2018). AI should not 'compromise human freedom and autonomy by illegitimately and surreptitiously reducing options for and knowledge of citizens' (European Group on Ethics in Science and New Technologies 2018, p. 17).

\section{e. Self-determination}

There needs to be a balance between decision-making power that is freely given by the user to the autonomous systems and when this option is taken away or undermined by the system (Floridi et. al 2018). AI organisations should not manipulate individual's self-determination, particularly those who may be vulnerable to abuse (Rathenau Institute 2017, p. 26).

\section{f. Liberty}

AI organisations need to ensure that their AI protects individuals' liberties, as outlined in many human rights legislations, such as the EU's Charter of Fundamental Human Rights (2000) and the Universal Declaration of Human Rights (1948). iberty refers to rights such as freedom of speech, freedom of assembly, and freedom of movement. During the development of AI, there should be strong adherence to the protection of liberties, outlined in these fundamental human rights documents.

\section{g. Empowerment}

AI should be used to empower and strengthen our human rights, rather than curtailing or infringing upon them (ICDPPC 2018). If decisions are made about individuals that may harm their liberties, they should be empowered with the right to challenge such decisions (ICO 2017). 


\section{Trust}

Trust is such a fundamental principle for interpersonal interactions and is a foundational precept for society to function. Similarly, trust is being acknowledged as a key requirement for the ethical deployment and use of AI. The HLEG (2019) even use it as their defining paradigm for their ethics guidelines, referring to it throughout the entire document. It appears to be a relatively new phenomenon however, with most of the guidelines that make reference to trust coming after 2017.

\section{a. Trustworthiness}

AI organisations should prove they are trustworthy and that their technologies are reliable (Digital Decisions 2019; MI Garage 2019). End-users should be able to justly trust AI organisations to fulfil their promises and to ensure that their systems function as intended (Deutsche Telekom 2018; Institute of Business Ethics 2018; Microsoft 2018; Sony 2018; NITI Aayog 2018; and Microsoft 2017). Building trust should be encouraged by ensuring accountability, transparency, and safety of AI (Royal Society 2017). Organisations can cultivate trust by demonstrating the security of their AI (Intel 2017) and guard the data retrieved from these systems in a responsible way (Unity Blog 2018).

\section{Sustainability}

Sustainability is a key principle in global discussions at present and its importance is only set to rapidly increase as a result of climate change predictions and ongoing environmental destruction. All fields and disciplines are affected and need to incorporate sustainability agendas, and AI is no exception. Despite this, it did not appear as an overly pressing concern in the majority of guidelines, demonstrating a greater need to identify how it can be incorporated more effectively.

\section{a. Sustainability}

AI organisations need to ensure that they are environmentally sustainable and incorporate environmental outcomes within their decision-making (Special Interest Group on Artificial Intelligence 2018). There must be an adherence to resource-efficient, sustainable energypromoting and the protection of biodiversity, by the AI.

\section{b. Environment (nature)}

Organisations should use AI that has been developed in an environmentally conscious manner (SIIA 2018). In situations where there is ecological harm caused by AI beyond acceptable levels, steps should be taken to either immediately halt it (temporarily or permanently); identify ways to use it in a non-harmful way; or consult the designers for potential solutions and responses. AI should not be used to harm biodiversity (UNI Global 2017).

\section{c. Energy}

The use of AI should be respectful of energy efficiency, mitigate greenhouse gas emissions, and protect biodiversity (Université de Montréal 2017). Those responsible for AI should ensure 
that its ecological footprint is minimal and all efforts are taken to reduce emission levels (Green Digital Working Group 2016, p. 7).

\section{d. Resources (energy)}

AI should be created in a way that ensures effective energy and resource consumption, promotes resource efficiency, the use of renewable materials, and reduction of use of scarce materials and minimal waste (European Parliament 2017). Resource use and environmental impact should be held in importance in the life cycle impact assessment of AI (COMEST/UNESCO 2017, p. 55).

\section{Dignity}

Human dignity is the recognition that individuals have inherent worth and that their rights should be respected. It is important that AI does not infringe or harm the dignity of end-users or other members within society. Respecting individuals' dignity is a vital principle that should be taken into account within AI ethics guidelines.

\section{a. Dignity}

Human beings have intrinsic value and developers/organisational users should ensure that this is respected in the design and use of AI (The Conference toward AI Network Society 2017). AI should be developed and used in a way that 'respects, serves and protects humans' physical and mental integrity, personal and cultural sense of identity, and satisfaction of their essential needs' (HLEG 2019, p. 10). AI needs to be developed and used in a way that makes it clear to the user that they are interacting with AI and not another human being (EGE 2018). Efforts need to be made to ensure that AI is not confused with human beings, as dignity is a value inherent to human beings (COMEST/UNESCO 2017, p. 50). Organisations should ensure that their AI does not violate the end-user's dignity and should closely follow the principle of dignity outlined in the first chapter of the EU Charter (Latonero 2018).

\section{Solidarity}

With the widespread use of AI to disseminate fake news, its potential to surveil and invade individuals' privacy, there is a growing concern that AI may be used to undermine and jeopardise societal relationships and solidarity. It is important to consider if the AI supports rich and meaningful social interaction, both professionally and in private life, and not support segregation and division, within the design and development process. AI should promote social security and cohesion, and should not jeopardise societal bonds and relationships.

\section{a. Solidarity}

AI should be developed to promote, or avoid harm to, societal bonds and relationships between people and generations (Université de Montréal 2017). AI should facilitate and promote human development, rather than being designed to obstruct or endanger it (ICDPPC 2018). There should be consideration towards preserving and promoting solidarity and should not undermine 
existing social structures (Floridi et. al 2018). AI should not create 'social dislocation', whereby it adversely harm cultural and social identity, and those organisations that cause it should be held responsible (Accenture 2019).

\section{b. Social Security}

Democratic values should not be jeopardised as a result of AI use and citizens should receive accurate and impartial information without interference or manipulation for political purposes (EGE 2018). AI should not be developed or used to undermine electoral and political decisionmaking (HLEG 2019). This can be done by ensuring that democratic values are promoted in AI development and implementation (EGE 2018).

\section{c. Cohesion}

AI organisations should promote fair distribution of benefits from AI to ensure social cohesion is not harmed (Koski \& Husso 2018, p. 51). The use of AI should contribute to global justice, in the aim to promote social cohesion and solidarity (European Group on Ethics in Science and New Technologies 2018, p. 17). AI teams should not develop or use these technologies in a way that knowingly undermines 'functioning democratic systems of government' (Unity Blog 2018). AI organisations should actively develop strategies with academia, civil society and industry partners, to promote social cohesion and knowledge-exchange collaborations (Privacy International 2018, p. 29).

\section{Discussion and Conclusion}

Maybe the first impression arising from this long and, as we hope, comprehensive overview of AI ethics guidance is that there is a diversity of ethical principles, issues and concerns that are covered by a large number of guidelines. Even focusing on organisational users and developers and leaving out stakeholder groups like policymakers, as we have done in this paper, the list is impressive. One of the points of criticism sometimes levelled at the dominant approach to principle-based guidelines is that they can oversimplify complex and difficult ethical debates and lead to an appearance of moral consensus where in fact the difficult ethical questions are hidden in the details of the application of principles (Mittelstadt, 2019). We hope that our work goes some way towards addressing this concern. In determining the constituent ethical issues and identifying normative positions arising from these, we provide a rich overview of guidance that is available to developers and users of AI. We believe that this is valuable to academic researchers and individuals who develop or revise ethical guidelines. By providing a comprehensive set of guidelines these stakeholders can now assess the completeness of their work. We are not suggesting that there should only be one set of guidelines that cover everything, but scholars working on guidelines, e.g. for particular application areas, can use our work to validate their work. Furthermore, we believe that the guidelines can be useful to developers and users who would like to understand the ethical challenges they can face and should be prepared to engage with. Our contribution is thus both academic / theoretical and practical.

Having said this, we realise that this paper can only be an intermediary step to a more manageable and practical set of guidance. One step that should now be undertaken is to do a philosophical and conceptual analysis of the guidance provided in these documents. Key 
questions to be asked include how the individual principles and their constituent issues can be justified from a philosophical perspective. This analysis should form part of a greater check for consistency of the guidelines. We have identified and categorised the components of many existing guidelines, but we have not checked whether and to what degree these are consistent.

A further step will be the exploration of potential conflicts between individual principles. A typical example well discussed in the literature are conflicts between privacy and transparency. Many other conflicts are easily imaginable. A practical set of guidelines that developers and users of AI can apply in practice needs to be aware of such conflicts and provide mechanisms for identifying them and dealing with them in an appropriate way.

On their way to being truly practicable, guidelines also need to go even further into detail than we have and at least provide pointers to ways of realising and implementing normative statements. It is important to understand that one should do X, but at the same time, this is not helpful, if one does not know how to do X. There are by now large numbers of tools and initial attempts to collect and categories them that help address various ethical issues of AI (Morley et al., 2019). What is required now is to map these tools against the ethical guidelines to allow individuals and organisations to adopt these norms in practice.

And, finally, there needs to be ways to integrate the guidelines as presented here to address ethical issues in AI. They may, for example, find their way into standards, they can form parts of corporate or industry governance mechanisms, they can be reflected in legislation and regulation and be enforced by regulators. We tried in this paper to provide a detailed account of guidance that is available to developers and users, but we realise that these are unlikely to have much practical effect, if they simply remain aspirational documents which, to exacerbate matters, are long, wordy and difficult to digest.

It is thus clear that this paper can only be one step in a longer journey towards a more comprehensive approach to dealing with the ethics of AI. We hope to have shown, however, that this step is a crucially important one that is required to progress both theoretically and practically. In this spirit we hope that the paper finds a broad audience and can provide the input into the next steps that are no doubt required.

\section{References}

Accenture (2019) Responsible AI and robotics: an ethical framework

ACM (2017) Statement on Algorithmic Transparency and Accountability

ADMA (Association for Data-driven Marketing and Advertising) (ADMA) (2013) Best practice guideline: Big Data

AGID (2018) L’Intelligenzia Artificiale al Servizio del Cittadino

AI for Humanity (2018) For a Meaningful Artificial Intelligence: Towards a French and European Strategy

AI Now Institute (2016) The AI Now Report: The Social and Economic Implications of Artificial Intelligence Technologies in the Near-Term

AI Now Institute (2017) AI Now 2017 Report 
AI Now Institute (2018) AI Now Report 2018

Algo.Rules (2019) Rules for the Design of Algorithmic Systems

Allistene (2014) Éthique de la Recherche en Robotique

AMA (2018) Policy Recommendations on Augmented Intelligence in Health Care H-480.940

American College of Radiology (2019) Ethics of AI in Radiology: European and North American Multisociety Statement

Amnesty International / Access Now (2018) The Toronto Declaration: Protecting the rights to equality and non-discrimination in machine learning systems, Available at:

https://www.accessnow.org/cms/assets/uploads/2018/08/The-Toronto-Declaration_ENG_082018.pdf

Aronson J (1995) A pragmatic view of thematic analysis. The qualitative report 2:1-3

Asilomar Conference (2017) Asilomar AI Principles. In: Future of Life Institute.

https://futureoflife.org/ai-principles/. Accessed 10 Feb 2018

Australian Government (2019) Artificial Intelligence: Australia’s Ethics Framework

B Debate (2017) Barcelona Declaration for the Proper Development and Usage of Artificial Intelligence in Europe

Beauchamp TL, Childress JF (1979) Principles of Biomedical Ethics. Oxford University Press, Oxford

Berendt B (2019) AI for the Common Good?! Pitfalls, challenges, and ethics pen-testing. Paladyn, Journal of Behavioral Robotics 10:44-65 . https://doi.org/10.1515/pjbr-2019-0004

Bertelsmann Stiftung and iRights.Lab (2019) Algo.Rules - Rules for the Design of Algorithmic Systems

Braun V, Clarke V (2006) Using thematic analysis in psychology. Qualitative research in psychology 3:77-101

Bynum TW (2010) The historical roots of information and computer ethics. In: Floridi L (ed) The Cambridge Handbook of Information and Computer Ethics. Cambridge University Press, pp 20-38

Bynum TW, Rogerson S (2003) Computer Ethics and Professional Responsibility: Introductory Text and Readings. WileyBlackwell

Capurro R (2008) On Floridi's metaphysical foundation of information ecology. Ethics and Information Technology 10:167

Center for Democracy and Technology (2019) Digital decisions

Cerna Collectif (2018) Research Ethics in Machine Learning

Childress JF, Beauchamp TL (1979) Principles of biomedical ethics. Oxford University Press 
Clark R (2019) Principles for AI: A SourceBook

CNIL (2017) How Can Humans Keep the Upper Hand? The Ethical Matters Raised by Algorithms and Artificial Intelligence

COMEST/UNESCO (2017) Report of COMEST on Robotics Ethics

Commission Nationale de l'Informatique et des Libertés, European Data Protection

Supervisor \& Garante per la protezione dei dati personali (2018) Declaration on Ethics and Data Protection in Artificial Intelligence

Council of Europe (2017) Guidelines on the protection of individuals with regard to the processing of personal data in a world of Big Data

Council of Europe (2019) European ethical charter on the use of artificial intelligence in judicial systems and their environment

Datatilsynet (2018) Artificial Intelligence and Privacy

Dawson, D. et al. (2019) Artificial Intelligence: Australia's Ethics Framework, Australian Government.

DeepMind (2017) DeepMind ethics and society principles

Demiaux, V., \& Abdallah, Y. S. (2017) How Can Humans Keep the Upper Hand? The Ethical Matters Raised by Algorithms and Artificial Intelligence. Report on the public debate led by the French Data Protection Authority (CNIL) as part of the ethical discussion assignment set by the Digital Republic Bill. Paris: CNIL.

Deutsche Telekom (2018) Guidelines for artificial intelligence

Digital decisions (2019) Center for Democracy \& Technology, https://cdt.org/issue/privacydata/digital-decisions/

EPSRC (2011) Principles of robotics

European Group on Ethics in Science and New Technologies (2018) Statement on Artificial Intelligence, Robotics and 'Autonomous' Systems

European Parliament (2017) Report with Recommendations to the Commission on Civil Law Rules on Robotics

European Union (2000) Charter of Fundamental Human Rights (2000/C 364/01)

Executive Office of the President (2016a) Preparing for the Future of Artificial Intelligence. Executive Office of the President National Science and Technology Council Committee on Technology

Executive Office of the President (2016b) Artificial Intelligence, Automation, and the Economy. Executive Office of the President National Science and Technology Council Committee on Technology 
FATML (2016) Principles for accountable algorithms and a social impact statement for algorithms

Federal Ministry of Transport and Digital Infrastructure (2017) Ethics Commission: Automated and Connected Driving

Floridi, L., Cowls, J., Beltrametti, M., Chatila, R., Chazerand, P., Dignum, V., ... \& Schafer, B. (2018) AI4People-An ethical framework for a good AI society: Opportunities, risks, principles, and recommendations. Minds and Machines, 28(4), 689-707.

Floridi L (2019) Establishing the rules for building trustworthy AI. Nature Machine Intelligence $1 . \mathrm{https}$ //doi.org/10.1038/s42256-019-0055-y

Future Advocacy (2019) Fenech, M., Strukelj, N. \& Buston, O. Ethical, Social, and Political Challenges of Artificial Intelligence in Health

Future of Life Institute (2017) Asilomar AI Principles

Future of Life Institute (2018) National and international AI strategies

Gilburt, B. (2019) Women leading in AI: 10 principles of responsible AI. Towards Data Science https://towardsdatascience.com/women-leading-in-ai-10-principles-for-responsibleai-8a167fc09b7d.

Google AI (2019) Artificial intelligence at Google: our principles

GOV UK (2018) Data Ethics Framework

GOV UK (2019) Initial code of conduct for data-driven health and care technology

Government of the Republic of Korea (2017) Mid- to Long-Term Master Plan in Preparation for the Intelligent Information Society: Managing the Fourth Industrial Revolution

Green Digital Working Group (2016) Position on Robotics and Artificial Intelligence

Haenlein M, Kaplan A (2019) A brief history of artificial intelligence: On the past, present, and future of artificial intelligence. California Management Review 61:5-14

High-Level Expert Group on AI (2019) Ethics Guidelines for Trustworthy AI

HLEG on AI HEG on AI (2019) Ethics Guidelines for Trustworthy AI. European Commission - Directorate-General for Communication, Brussels

HoL (2018) AI in the UK: ready, willing and able? Select Committee on Artificial Intelligence, London

House of Commons Science and Technology Committee (2016) Robotics and artificial intelligence

IBM (2018) Everyday Ethics for Artificial Intelligence 
IBM (2017) Transparency and trust in the cognitive era.

https://www.ibm.com/blogs/think/2017/01/ibm-cognitive-principles/

ICDPPC (International Conference of Data Protection and Privacy Commissioners) (2018)

Declaration on Ethics and Data Protection in Artificial Intelligence, Available at:

https://icdppc.org/wp-content/uploads/2018/10/20180922_ICDPPC-40th_AI-

Declaration_ADOPTED.pdf

ICO (2017) Big Data, Artificial Intelligence, Machine Learning and Data Protection

IEEE (2017) Ethically Aligned Design: A Vision for Prioritizing Human Well-being with Autonomous and Intelligent Systems, Version 2

IEEE (2019) Ethically Aligned Design: A Vision for Prioritizing Human Well-being with Autonomous and Intelligent Systems, Version 1

IIIM (2015) Ethics Policy

IPC Ontario (Information and Privacy Commissioner of Ontario) (2017) Big Data Guidelines

Institute of Business Ethics (2018) Business Ethics and Artificial Intelligence

Intel (2017) Artificial Intelligence: The Public Policy Opportunity

Intel (2018) Intel's AI Privacy Policy White Paper: Protecting Individuals' Privacy and Data In The Artificial Intelligence World

Internet Society (2017) Artificial intelligence and machine learning: policy paper

ITI (2017) ITI AI Policy Principles

Japanese Society for Artificial Intelligence (2017) The Japanese Society for Artificial Intelligence Ethical Guidelines

Jobin, A., Ienca, M. \& Vayena, E. (2019) The global landscape of AI ethics guidelines. Nat Mach Intell 1, 389-399. https://doi.org/10.1038/s42256-019-0088-2

Johnson K, Pasquale F, Chapman J (2019) Artificial Intelligence, Machine Learning, and Bias in Finance: Toward Responsible Innovation. Fordham Law Review 88:499

Kaplan A, Haenlein M (2019) Siri, Siri, in my hand: Who's the fairest in the land? On the interpretations, illustrations, and implications of artificial intelligence. Business Horizons $62: 15-25$

Koski, O. \& Husso, K. (2018) Work in the Age of Artificial Intelligence, Ministry of Economic Affairs and Employment.

Latonero M (2018) Governing artificial intelligence: upholding human rights \& dignity. Data \& Society

Leaders of the G7 (2018) Common Vision for the Future of Artificial Intelligence

MI Garage (2019) Ethics framework 
Microsoft (2017) Microsoft AI principles. Microsoft

Microsoft (2018) Responsible bots: 10 guidelines for developers of conversational AI

Ministry of Economic Affairs and Employment (2018) Work in the Age of Artificial Intelligence

Ministry of State for Science and Technology Policy (2019) Report on Artificial Intelligence and Human Society: Unofficial Translation

Mittelstadt B (2019) Principles alone cannot guarantee ethical AI. Nature Machine Intelligence 2019: . https://doi.org/doi:10.1038/s42256-019-0114-4

Moor JH (1985) What is computer ethics. Metaphilosophy 16:266-275

Morley, J., Floridi, L., Kinsey, L. and Elhalal., A. (2019) From What to How: An Initial Review of Publicly Available AI Ethics Tools, Methods and Research to Translate Principles into Practices. Sci Eng Ethics. https://doi.org/10.1007/s11948-019-00165-5

NITI Aayog (2018) Discussion Paper: National Strategy for Artificial Intelligence

NSTC (2016a) Preparing for the future of Artificial Intelligence

NSTC (2016b) The National Artificial Intelligence Research and Development Strategic Plan

O’Neil, C. (2016) Weapons of Math Destruction: How Big Data Increases Inequality and Threatens Democracy, Crown Publishers.

OECD (2019) Recommendation of the Council on Artificial Intelligence.

OP (2019) Commitments and principles.

OpenAI (2018) OpenAI Charter

Personal Data Protection Commission Singapore (2018) Discussion Paper on AI and Personal Data - Fostering Responsible Development and Adoption of AI

Personal Data Protection Commission Singapore (2019) A Proposed Model Artificial Intelligence Governance Framework

Privacy International/Article 19 (2018) Privacy and Freedom of Expression in the Age of Artificial Intelligence

PwC (2019) The responsible AI framework

Rathenau Institute (2017) Human Rights in the Robot Age: Challenges Arising from the Use of Robotics, Artificial Intelligence, and Virtual and Augmented Reality

RCP London (2018) Artificial intelligence (AI) in health 
Royal Society (2017) Machine Learning: The Power and Promise of Computers that Learn by Example

Ryan, M. (2019a) Ethics of Using AI and Big Data in Agriculture: The Case of a Large Agriculture Multinational. ORBIT Journal, 2(2). https://doi.org/10.29297/orbit.v2i2.109

Ryan, M. (2019b) Ethics of Public Use of AI and Big Data. ORBIT Journal, 2(2). https://doi.org/10.29297/orbit.v2i1.101

Ryan, M. (2019c) The Future of Transportation: Ethical, Legal, Social and Economic Impacts of Self-driving Vehicles in the Year 2025. Sci Eng Ethics. https://doi.org/10.1007/s11948019-00130-2

Ryan, M., \& Gregory, A. (2019) Ethics of Using Smart City AI and Big Data: The Case of Four Large European Cities. ORBIT Journal, 2(2). https://doi.org/10.29297/orbit.v2i2.110

Sage (2017) The Ethics of Code: Developing AI for Business with Five Core Principles

SAP (2018) SAP's guiding principles for artificial intelligence (AI)

SIIA (2017) Ethical Principles for Artificial Intelligence and Data Analytics

Smart Dubai (2019) Artificial intelligence principles and ethics

Sony (2018) Sony Group AI Ethics Guidelines

Special Interest Group on Artificial Intelligence (2018) Dutch Artificial Intelligence Manifesto

Stix C (2019) A survey of the European Union's artificial intelligence ecosystem. Leverhulme Centre for the Future of Intelligence, Cambridge

Telefónica (2018) AI principles of Telefónica

The Conference toward AI Network Society (2017) Draft AI R\&D Guidelines for International Discussions

The Future Society (2018) Science, law and society (SLS) initiative

The Information Accountability Foundation (2015) Unified Ethical Frame for Big Data Analysis: IAF Big Data Ethics Initiative, Part A

The Partnership on AI (2016) Tenets

The Public Voice (2018) Universal guidelines for artificial intelligence

Tieto (2018) Tieto’s AI Ethics Guidelines

Towards Data Science (2019) Women leading in AI: 10 principles of responsible AI

UK Government (2018) Department for Digital, Culture, Media \& Sport, Data Ethics Framework, Available at: 
https://assets.publishing.service.gov.uk/government/uploads/system/uploads/attachment_data /file/737137/Data_Ethics_Framework.pdf

UNI Global (2017) Top 10 Principles for Ethical AI

United Nations (1948) Universal Declaration of Human Rights, (General Assembly resolution $217 \mathrm{~A}$ )

United Nations Development Group (UNDG) (2017) Data Privacy, Ethics and Protection. Guidance Note on Big Data for Achievement of the 2030 Agenda

Unity Blog (2018) Introducing Unity’s Guiding Principles for Ethical AI

University of Montreal, "Montreal Declaration for a Responsible Development of Artificial Intelligence', 2017, Canada, Available at: https://www.montrealdeclarationresponsibleai.com/the-declaration

WEF (2018) White Paper: How to Prevent Discriminatory Outcomes in Machine Learning Wiener N (1954) The human use of human beings. Doubleday

World Wide Web Foundation (2018) Artificial Intelligence: Open Questions about Gender Inclusion 
Appendix 1: Ethics Guidelines Used

\begin{tabular}{|c|c|c|}
\hline Name of document/website & Issuer & Country \\
\hline $\begin{array}{ll}\text { Artificial } & \text { Intelligence. } \\
\text { Australia's Ethics } & \text { Framework: } \\
\text { A Discussion Paper }\end{array}$ & $\begin{array}{l}\text { Department of Industry Innovation and } \\
\text { Science }\end{array}$ & Australia \\
\hline $\begin{array}{l}\text { Best practice guideline: Big } \\
\text { Data }\end{array}$ & $\begin{array}{l}\text { Association for Data-driven Marketing } \\
\text { and Advertising (ADMA) }\end{array}$ & Australia \\
\hline $\begin{array}{l}\text { Montréal } \quad \text { Declaration: } \\
\text { Responsible Al }\end{array}$ & Université de Montréal & Canada \\
\hline Big Data Guidelines & $\begin{array}{l}\text { IPC Ontario (Information and Privacy } \\
\text { Commissioner of Ontario) }\end{array}$ & Canada \\
\hline $\begin{array}{l}\text { Work in the Age of Artificial } \\
\text { Intelligence. Four Perspectives } \\
\text { on the Economy, Employment, } \\
\text { Skills and Ethics }\end{array}$ & $\begin{array}{l}\text { Ministry of Economic Affairs and } \\
\text { Employment }\end{array}$ & Finland \\
\hline Tieto's AI Ethics Guidelines & Tieto & Finland \\
\hline Commitments and Principles & OP Group & Finland \\
\hline $\begin{array}{l}\text { How Can Humans Keep the } \\
\text { Upper Hand? Report on the } \\
\text { Ethical Matters Raised by Al } \\
\text { Algorithms }\end{array}$ & French Data Protection Authority (CNIL) & France \\
\hline $\begin{array}{l}\text { For a Meaningful Artificial } \\
\text { Intelligence. Towards a French } \\
\text { and European Strategy }\end{array}$ & Al for Humanity & France \\
\hline $\begin{array}{l}\text { Ethique de la Recherche en } \\
\text { Robotique }\end{array}$ & CERNA (Allistene) & France \\
\hline Al Guidelines & Deutsche Telekom & Germany \\
\hline $\begin{array}{l}\text { SAP's Guiding Principles for } \\
\text { Artificial Intelligence }\end{array}$ & SAP & Germany \\
\hline $\begin{array}{l}\text { Automated and Connected } \\
\text { Driving: Report }\end{array}$ & $\begin{array}{l}\text { Federal Ministry of Transport and Digital } \\
\text { Infrastructure, Ethics Commission }\end{array}$ & Germany \\
\hline $\begin{array}{l}\text { Rules for the Design of } \\
\text { Algorithmic Systems }\end{array}$ & Algo.Rules & Germany \\
\hline Ethics Policy & $\begin{array}{l}\text { Icelandic Institute for Intelligent Machines } \\
\text { (IIIM) }\end{array}$ & Iceland \\
\hline
\end{tabular}




\begin{tabular}{|c|c|c|}
\hline $\begin{array}{lll}\text { Discussion } & \text { Paper: } & \text { National } \\
\text { Strategy } & \text { for } & \text { Artificial } \\
\text { Intelligence } & & \end{array}$ & $\begin{array}{l}\text { National Institution for Transforming India } \\
\text { (NITI Aayog) }\end{array}$ & India \\
\hline $\begin{array}{l}\text { L'intelligenzia Artificiale al } \\
\text { Servizio del Cittadino }\end{array}$ & Agenzia per l'Italia Digitale (AGID) & Italy \\
\hline $\begin{array}{l}\text { The Japanese Society for } \\
\text { Artificial Intelligence Ethical } \\
\text { Guidelines }\end{array}$ & Japanese Society for Artificial Intelligence & Japan \\
\hline $\begin{array}{l}\text { Report on Artificial Intelligence } \\
\text { and Human Society (unofficial } \\
\text { translation) }\end{array}$ & $\begin{array}{l}\text { Advisory Board on Artificial Intelligence } \\
\text { and Human Society (initiative of the } \\
\text { Minister of State for Science and } \\
\text { Technology Policy) }\end{array}$ & Japan \\
\hline $\begin{array}{l}\text { Draft } \mathrm{Al} \text { R\&D Guidelines for } \\
\text { International Discussions }\end{array}$ & $\begin{array}{l}\text { Institute for Information and } \\
\text { Communications Policy (IICP), The } \\
\text { Conference toward Al Network Society }\end{array}$ & Japan \\
\hline $\begin{array}{l}\text { Sony Group Al Ethics } \\
\text { Guidelines }\end{array}$ & Sony & Japan \\
\hline $\begin{array}{l}\text { Human Rights in the Robot } \\
\text { Age Report }\end{array}$ & The Rathenau Institute & Netherlands \\
\hline $\begin{array}{l}\text { Dutch Artificial Intelligence } \\
\text { Manifesto }\end{array}$ & $\begin{array}{l}\text { Special Interest Group on } \\
\text { Intelligence (SIGAI), ICT } \\
\text { Netherlands (IPN) }\end{array}$ & Netherlands \\
\hline $\begin{array}{l}\text { Artificial Intelligence and } \\
\text { Privacy }\end{array}$ & The Norwegian Data Protection Authority & Norway \\
\hline $\begin{array}{l}\text { Discussion Paper on Artificial } \\
\text { Intelligence (AI) and Personal } \\
\text { Data-Fostering Responsible } \\
\text { Development and Adoption of } \\
\mathrm{Al}\end{array}$ & $\begin{array}{l}\text { Personal Data Protection Commission } \\
\text { Singapore }\end{array}$ & Singapore \\
\hline $\begin{array}{l}\text { A Proposed Model Artificial } \\
\text { Intelligence } \quad \text { Governance } \\
\text { Framework }\end{array}$ & $\begin{array}{l}\text { Personal Data Protection Commission } \\
\text { Singapore }\end{array}$ & Singapore \\
\hline $\begin{array}{l}\text { Mid- to Long-Term Master Plan } \\
\text { in Preparation for the Intelligent } \\
\text { Information Society }\end{array}$ & Government of the Republic of Korea & South Korea \\
\hline Al Principles of Telefónica & Telefónica & Spain \\
\hline $\begin{array}{l}\text { Barcelona Declaration for } \\
\text { the Proper Development and } \\
\text { Usage of Artificial } \\
\text { Intelligence in Europe }\end{array}$ & B Debate & Spain \\
\hline Al Principles \& Ethics & Smart Dubai & UAE \\
\hline
\end{tabular}




\begin{tabular}{|c|c|c|}
\hline Principles of robotics & $\begin{array}{l}\text { Engineering and Physical Sciences } \\
\text { Research Council UK (EPSRC) }\end{array}$ & UK \\
\hline $\begin{array}{l}\text { The Ethics of Code: } \\
\text { Developing Al for Business } \\
\text { with Five Core Principles }\end{array}$ & Sage & UK \\
\hline $\begin{array}{l}\text { Big Data, Artificial Intelligence, } \\
\text { Machine Learning and Data } \\
\text { Protection }\end{array}$ & Information Commissioner's Office & UK \\
\hline $\begin{array}{l}\text { DeepMind Ethics \& Society } \\
\text { Principles }\end{array}$ & DeepMind Ethics \& Society & UK \\
\hline $\begin{array}{l}\text { Business Ethics and Artificial } \\
\text { Intelligence }\end{array}$ & Institute of Business Ethics & UK \\
\hline $\begin{array}{l}\text { Al in the UK: Ready, Willing } \\
\text { and Able? }\end{array}$ & $\begin{array}{l}\text { UK House of Lords, Select Committee on } \\
\text { Artificial Intelligence }\end{array}$ & UK \\
\hline $\begin{array}{l}\text { Artificial Intelligence }(\mathrm{Al}) \text { in } \\
\text { Health }\end{array}$ & Royal College of Physicians & UK \\
\hline $\begin{array}{l}\text { Initial Code of Conduct for } \\
\text { Data-Driven Health and Care } \\
\text { Technology }\end{array}$ & UK Department of Health \& Social Care & UK \\
\hline $\begin{array}{l}\text { Department for Digital, } \\
\text { Culture, Media \& Sport, Data } \\
\text { Ethics Framework }\end{array}$ & UK Government & UK \\
\hline $\begin{array}{l}\text { Ethics } \quad \text { Framework: } \\
\text { Responsible Al }\end{array}$ & $\begin{array}{l}\text { Machine Intelligence Garage Ethics } \\
\text { Committee }\end{array}$ & UK \\
\hline $\begin{array}{l}\text { The Responsible } \quad \mathrm{Al} \\
\text { Framework }\end{array}$ & PricewaterhouseCoopers UK & UK \\
\hline $\begin{array}{l}\text { Responsible Al and Robotics. } \\
\text { An Ethical Framework. }\end{array}$ & Accenture UK & UK \\
\hline $\begin{array}{l}\text { Machine Learning: The Power } \\
\text { and Promise of Computers that } \\
\text { Learn by Example }\end{array}$ & The Royal Society & UK \\
\hline $\begin{array}{l}\text { Ethical, Social, and Political } \\
\text { Challenges of } \\
\text { Intelligence in Health }\end{array}$ & Future Advocacy & UK \\
\hline $\begin{array}{l}\text { Unified Ethical Frame for Big } \\
\text { Data Analysis. IAF Big Data } \\
\text { Ethics Initiative, Part A }\end{array}$ & $\begin{array}{l}\text { The Information } \\
\text { Foundation }\end{array}$ & USA \\
\hline $\begin{array}{l}\text { The AI Now Report. The Social } \\
\text { and Economic Implications of } \\
\text { Artificial Intelligence } \\
\text { Technologies in the Near-Term }\end{array}$ & Al Now Institute & USA \\
\hline
\end{tabular}




\begin{tabular}{|c|c|c|}
\hline $\begin{array}{lr}\text { Statement on } & \text { Algorithmic } \\
\text { Transparency } & \text { and } \\
\text { Accountability } & \end{array}$ & $\begin{array}{l}\text { Association for Computing Machinery } \\
\text { (ACM) }\end{array}$ & USA \\
\hline Al Principles & Future of Life Institute & USA \\
\hline Al-Our Approach & Microsoft & USA \\
\hline $\begin{array}{l}\text { Artificial Intelligence. The } \\
\text { Public Policy Opportunity }\end{array}$ & Intel Corporation & USA \\
\hline $\begin{array}{l}\text { IBM's Principles for Trust and } \\
\text { Transparency }\end{array}$ & IBM & USA \\
\hline OpenAl Charter & OpenAl & USA \\
\hline Our Principles & Google & USA \\
\hline $\begin{array}{l}\text { Policy Recommendations on } \\
\text { Augmented Intelligence in } \\
\text { Health Care } \mathrm{H}-480.940\end{array}$ & American Medical Association (AMA) & USA \\
\hline $\begin{array}{l}\text { Everyday Ethics for Artificial } \\
\text { Intelligence. A Practical Guide } \\
\text { for Designers and Developers }\end{array}$ & IBM & USA \\
\hline $\begin{array}{l}\text { Governing Artificial } \\
\text { Intelligence. Upholding Human } \\
\text { Rights \& Dignity }\end{array}$ & Latonero et al. & USA \\
\hline $\begin{array}{l}\text { Intel's Al Privacy Policy White } \\
\text { Paper. Protecting Individuals' } \\
\text { Privacy and Data in the } \\
\text { Artificial Intelligence World }\end{array}$ & Intel Corporation & USA \\
\hline $\begin{array}{l}\text { Introducing Unity's Guiding } \\
\text { Principles for Ethical Al-Unity } \\
\text { Blog }\end{array}$ & Unity Technologies & USA \\
\hline Digital Decisions & Center for Democracy \& Technology & USA \\
\hline $\begin{array}{l}\text { Science, Law and Society } \\
\text { (SLS) Initiative }\end{array}$ & The Future Society & USA \\
\hline AI Now 2018 Report & Al Now Institute & USA \\
\hline $\begin{array}{l}\text { Responsible Bots: } 10 \\
\text { Guidelines for Developers of } \\
\text { Conversational Al }\end{array}$ & Microsoft & USA \\
\hline
\end{tabular}


Preparing for the Future of Artificial Intelligence

The National Artificial
Intelligence Research and
Development Strategic Plan

Executive Office of the President; National Science and Technology Council; Committee on Technology Development Strategic Plan

National Science and Technology Council; Networking and Information Technology Research and Development Subcommittee

\begin{tabular}{|c|c|c|}
\hline Al Now 2017 Report & Al Now Institute & USA \\
\hline $\begin{array}{l}\text { Position on Robotics and } \\
\text { Artificial Intelligence }\end{array}$ & $\begin{array}{l}\text { The Greens (Green Working Group } \\
\text { Robots) }\end{array}$ & EU \\
\hline $\begin{array}{l}\text { Report with Recommendations } \\
\text { to the Commission on Civil Law } \\
\text { Rules on Robotics }\end{array}$ & European Parliament & EU \\
\hline $\begin{array}{l}\text { Ethics Guidelines for } \\
\text { Trustworthy Al }\end{array}$ & $\begin{array}{l}\text { High-Level Expert Group on Artificial } \\
\text { Intelligence }\end{array}$ & EU \\
\hline $\begin{array}{l}\text { Al4People_An Ethical } \\
\text { Framework for a Good Al } \\
\text { Society: Opportunities, Risks, } \\
\text { Principles, } \\
\text { Recommendations }\end{array}$ & Al4People & $\mathrm{EU}$ \\
\hline $\begin{array}{l}\text { European Ethical Charter on } \\
\text { the Use of Artificial Intelligence } \\
\text { in Judicial Systems and Their } \\
\text { Environment }\end{array}$ & $\begin{array}{l}\text { Council of Europe: European Commission } \\
\text { for the Efficiency of Justice (CEPEJ) }\end{array}$ & $\mathrm{EU}$ \\
\hline $\begin{array}{l}\text { Guidelines on the protection } \\
\text { of individuals with regard to } \\
\text { the processing of personal } \\
\text { data in a world of Big Data }\end{array}$ & $\begin{array}{l}\text { Council of Europe: European } \\
\text { Commission for the Efficiency of } \\
\text { Justice (CEPEJ) }\end{array}$ & EU \\
\hline $\begin{array}{l}\text { Statement on Artificial } \\
\text { Intelligence, Robotics and } \\
\text { 'Autonomous' Systems }\end{array}$ & $\begin{array}{l}\text { European Commission, European Group } \\
\text { on Ethics in Science and New } \\
\text { Technologies }\end{array}$ & EU \\
\hline $\begin{array}{llr}\text { Artificial } & \text { Intelligence } & \text { and } \\
\text { Machine } & \text { Learning: } & \text { Policy } \\
\text { Paper } & & \end{array}$ & Internet Society & International \\
\hline $\begin{array}{l}\text { Report of COMEST on } \\
\text { Robotics Ethics }\end{array}$ & COMEST/UNESCO & International \\
\hline $\begin{array}{l}\text { Ethical Principles for Artificial } \\
\text { Intelligence and Data Analytics }\end{array}$ & $\begin{array}{l}\text { Software \& Information Industry } \\
\text { Association (SIIA), Public Policy Division }\end{array}$ & International \\
\hline ITI AI Policy Principles & $\begin{array}{l}\text { Information Technology Industry Council } \\
\text { (ITI) }\end{array}$ & International \\
\hline $\begin{array}{l}\text { Ethically Aligned Design. A } \\
\text { Vision for Prioritizing Human } \\
\text { Well-being with Autonomous }\end{array}$ & $\begin{array}{l}\text { Institute of Electrical and Electronics } \\
\text { Engineers (IEEE), The IEEE Global } \\
\text { Initiative on Ethics of Autonomous and }\end{array}$ & International \\
\hline
\end{tabular}




\begin{tabular}{|c|c|c|}
\hline $\begin{array}{l}\text { and Intelligent Systems, } \\
\text { Version } 2\end{array}$ & Intelligent Systems & \\
\hline $\begin{array}{l}\text { Top } 10 \text { Principles for Ethical } \\
\text { Artificial Intelligence }\end{array}$ & UNI Global Union & International \\
\hline $\begin{array}{l}\text { The Malicious Use of Artificial } \\
\text { Intelligence: Forecasting, } \\
\text { Prevention, and Mitigation }\end{array}$ & $\begin{array}{l}\text { Future of Humanity Institute; University of } \\
\text { Oxford; Centre for the Study of Existential } \\
\text { Risk; University of Cambridge; Center for } \\
\text { a New American Security; Electronic } \\
\text { Frontier Foundation; OpenAl }\end{array}$ & International \\
\hline $\begin{array}{l}\text { White Paper: How to Prevent } \\
\text { Discriminatory Outcomes in } \\
\text { Machine Learning }\end{array}$ & $\begin{array}{l}\text { WEF, Global Future Council on Human } \\
\text { Rights 2016-2018 }\end{array}$ & International \\
\hline $\begin{array}{l}\text { Privacy and Freedom of } \\
\text { Expression in the Age of } \\
\text { Artificial Intelligence }\end{array}$ & Privacy International \& Article 19 & International \\
\hline $\begin{array}{l}\text { The Toronto Declaration: } \\
\text { Protecting the Right to Equality } \\
\text { and Non-discrimination in } \\
\text { Machine Learning Systems }\end{array}$ & Access Now; Amnesty International & International \\
\hline $\begin{array}{l}\text { Charlevoix Common Vision for } \\
\text { the Future of Artificial } \\
\text { Intelligence }\end{array}$ & Leaders of the G7 & International \\
\hline $\begin{array}{l}\text { Artificial Intelligence: Open } \\
\text { Questions About Gender } \\
\text { Inclusion }\end{array}$ & W20 & International \\
\hline $\begin{array}{l}\text { Declaration on Ethics and Data } \\
\text { Protection in Artificial } \\
\text { Intelligence }\end{array}$ & ICDPPC & International \\
\hline $\begin{array}{l}\text { Universal Guidelines for } \\
\text { Artificial Intelligence }\end{array}$ & The Public Voice & International \\
\hline $\begin{array}{l}\text { Ethics of } \mathrm{Al} \text { in Radiology: } \\
\text { European and North American } \\
\text { Multisociety Statement }\end{array}$ & $\begin{array}{l}\text { American College of Radiology; European } \\
\text { Society of Radiology; Radiology Society } \\
\text { of North America; Society for Imaging } \\
\text { Informatics in Medicine; European Society } \\
\text { of Medical Imaging Informatics; Canadian } \\
\text { Association of Radiologists; American } \\
\text { Association of Physicists in Medicine }\end{array}$ & International \\
\hline $\begin{array}{l}\text { Ethically Aligned Design: A } \\
\text { Vision for Prioritizing Human } \\
\text { Well-being with Autonomous } \\
\text { and Intelligent Systems, First } \\
\text { Edition (EAD1e) }\end{array}$ & $\begin{array}{l}\text { Institute of Electrical and Electronics } \\
\text { Engineers (IEEE), The IEEE Global } \\
\text { Initiative on Ethics of Autonomous and } \\
\text { Intelligent Systems }\end{array}$ & International \\
\hline $\begin{array}{ll}\text { Recommendation of the } \\
\text { Council on } & \text { Artificial } \\
\text { Intelligence } & \end{array}$ & OECD & International \\
\hline
\end{tabular}




\begin{tabular}{|l|l|l|}
$\begin{array}{l}\text { Data Privacy, Ethics and } \\
\text { Protection. Guidance Note } \\
\text { on Big Data for Achievement } \\
\text { of the 2030 Agenda }\end{array}$ & $\begin{array}{l}\text { United Nations Development Group } \\
\text { (UNDG) }\end{array}$ & International \\
\hline Tenets & Partnership on Al N/A & N/A \\
\hline $\begin{array}{l}\text { Principles for Accountable } \\
\text { Stgorithms and a Social Impact }\end{array}$ & $\begin{array}{l}\text { Fairness, Accountability, } \\
\text { Transparency in Machine Learning } \\
\text { (FATML) }\end{array}$ & N/A \\
\hline 10 Principles of Responsible Al & Women Leading in Al & \\
\hline
\end{tabular}




\section{Artificial Intelligence Ethics Guidelines for Developers and Organisational Users - Clarifying the Content and Normative Implications of Ethical Principles}

\section{Response to reviewers}

We would like to thank the reviewers for their supportive feedback on the paper. They pointed out a number of important issues and we hope that we have done these justice in our revisions and the editor and reviewers now agree that the paper is in a state that is ready to be published.

The tables below provide the detailed response to the reviews

Reviewer 1

\begin{tabular}{|c|c|c|}
\hline Comment & Where it is changed & Response \\
\hline $\begin{array}{l}\text { 1. I found } 35 \text { mistakes of the } \\
\text { following kind: ( } 1 \text { ) incorrect } \\
\text { spelling (2) incorrect grammar } \\
\text { and (3) inapposite word/phrases. } \\
\text { These should be corrected. }\end{array}$ & $\begin{array}{l}\text { Throughout the } \\
\text { entire document. }\end{array}$ & $\begin{array}{l}\text { Apologies about the mistakes. We have proof- } \\
\text { read it several times to find these mistakes. } \\
\text { However, if you have the original document } \\
\text { where you marked the mistakes, we would } \\
\text { greatly appreciate it, in case we missed any of } \\
\text { them. }\end{array}$ \\
\hline $\begin{array}{l}\text { 2. It might be useful for the reader } \\
\text { if you had more examples of, for } \\
\text { example, harms. Additionally, } \\
\text { more examples of specific kinds of } \\
\text { Al. }\end{array}$ & N/A & $\begin{array}{l}\text { We deliberately tried to keep the examples of } \\
\text { harms and examples of specific types of Al to a } \\
\text { minimum because of the difficulty to narrow } \\
\text { down which ones to discuss, which would also } \\
\text { open us up to the charge of cherry-picking our } \\
\text { examples. } \\
\text { Most of the Al ethics guidelines are very broad } \\
\text { and do not provide specific harm examples or } \\
\text { kinds of Al, so we wanted to represent this. And } \\
\text { if they do, they are often in appendices or } \\
\text { additional information outside the main } \\
\text { guidelines themselves (e.g. the HLEG } \\
\text { guidelines). }\end{array}$ \\
\hline $\begin{array}{l}\text { 3. You might say something about } \\
\text { your use of normative/descriptive } \\
\text { terminology to explicate ethical } \\
\text { principles. Is there a principled } \\
\text { dividing line between the former } \\
\text { and the latter? Or would such a } \\
\text { dividing line depend upon }\end{array}$ & $\begin{array}{l}\text { Added to } \\
\text { Introduction: } \\
\text { "It must be made } \\
\text { clear here that we } \\
\text { are not providing } \\
\text { prescriptive } \\
\text { recommendations, } \\
\text { but rather, are }\end{array}$ & $\begin{array}{l}\text { We are mapping what the literature says what } \\
\text { we should do, we are not stating that these are } \\
\text { what organisations should do. } \\
\text { We clarify this point at the end of section 3: "As } \\
\text { our main interest was in determining which } \\
\text { guidance exists for developers and users of Al, } \\
\text { we distilled the guidance that was provided in }\end{array}$ \\
\hline
\end{tabular}




\section{Reviewer 2}

background knowledge of the user--to whom your article is addressed?

mapping the
prescriptive
recommendations
found in these
guidelines.

the guidelines. As a result our findings are strongly normative, i.e. they give guidance and instructions and are phrased accordingly (e.g. 'Al organisations should...'), rather than simply recounting what each guideline says on the matter. This is a result of our research approach and our interest in extracting guidance. The formulations we use in the next section does not imply that we are endorsing all of these guidelines or that we are suggesting that individuals always have to follow them. The meaning is that within the corpus of $\mathrm{Al}$ ethics guidelines there are suggestions that the indicated activities are morally appropriate. It falls outside of the scope of this paper to do a proper ethical analysis of the guidance, including their detailed ethical justification and check for consistency. "

\begin{tabular}{|c|c|c|}
\hline Comment & Where it is changed & Response \\
\hline $\begin{array}{l}\text { 1) it is not clear what the final list of } \\
\text { guidelines analysed ( } 94 \text { according to the } \\
\text { text) consists in. The final list of } 94 \text { items } \\
\text { analyzed is alleged to correspond to the } 84 \\
\text { of Jobin et al + some extra items I refer to } \\
\text { as X. As the readers can retrieve Jobin et } \\
\text { al's } 84 \text { guideline list in their articles, what is } \\
\text { crucial here is to know what additional } \\
\text { guidelines X comprises. If such list cannot } \\
\text { be provided in the main text (but why? A } \\
\text { footnote would suffice to specify the } 10 \\
\text { works included in X) the authors could } \\
\text { consider a link to additional material } \\
\text { available online, which provides the full list } \\
\text { of the guidelines analysed. }\end{array}$ & $\begin{array}{l}\text { Footnote } 2 \text { and } \\
\text { Appendix } 1\end{array}$ & $\begin{array}{l}\text { We have now included the } \\
\text { additional references into } \\
\text { footnote } 2 \text {. } \\
\text { We also provide a table } \\
\text { containing all sources in appendix } \\
1 .\end{array}$ \\
\hline $\begin{array}{l}\text { 2) I find it especially confusing, in the } \\
\text { absence of such list, that the authors would } \\
\text { cite documents such as Latonero's report or } \\
\text { Clark's document in the main text, along } \\
\text { other bona fide guideline documents. While } \\
\text { I do not have objections to cite non- } \\
\text { guideline documents to enrich the analysis } \\
\text { with theoretical elements, such work plays } \\
\text { a different role from the guidelines whose } \\
\text { text is analysed. Given point (1) leaving the } \\
\text { reader without the possibility of knowing if }\end{array}$ & Appendix 1 & $\begin{array}{l}\text { We have now included this list to } \\
\text { distinguish which of the additional } \\
\text { guidelines are ours. The Clarke } \\
\text { article is a secondary text. The } \\
\text { Latonero article is used by Jobin } \\
\text { et al. and we did not want to start } \\
\text { excluding certain texts from their } \\
\text { analysis because firstly it would } \\
\text { be very difficult to establish a } \\
\text { reason why, and also because it } \\
\text { would involve a certain amount of } \\
\text { cherry-picking on our part. We }\end{array}$ \\
\hline
\end{tabular}


the writings of Latonero and Clark's are considered primary sources (i.e. guidelines analysed) or secondary ones (i.e. further theoretical work on the topic, or on other guidelines) is highly problematic. Latonero's report proposes a five value framework but his text does not have the form of commands or prescriptions, but rather of analyses). Should it be included in the analysis as a guideline text? I doubt it. Clark's document (Principles for Al: A SourceBook), on the other hand, is not a primary source but a collation of principles from other codes. Hence, it is not clear to which of the original sources the cited guideline refers to. When the authors cite "Clark 2019" near a verbatim quote, it is not clear if this refers to Clark's original ideas or to the text of any other guideline he cites verbatim in the quoted document.

3) The most significant problem is that the breadth of the analysis is not fully demonstrated by the works cited. Excluding works such as Latonero and Clark, I have only counted 78 referenced sources (that I consider to be guidelines). What about the others? Please see my excel sheet where I count the cited guidelines and correct me if I am wrong. (It could also be that I am not counting *as guidelines* some texts that are cited in the text, e.g. Latonero or Clark, and others.)

4) I am especially unconvinced by this claim at the beginning of section 4: "[we] should state that we only provide key references. There is further overlap beyond the references provided here, but we did not want to render the text unreadable by providing too many references." While I understand that the practical readability of the text is an important constraint, there are other ways to tackle this citation challenge. The analysis would be considerable more useful if the authors could provide full account of the overlap - especially so, given that they give the impression to have performed the necessary analytical work, and to only limit their references due to formatting constraints. Providing full references to all

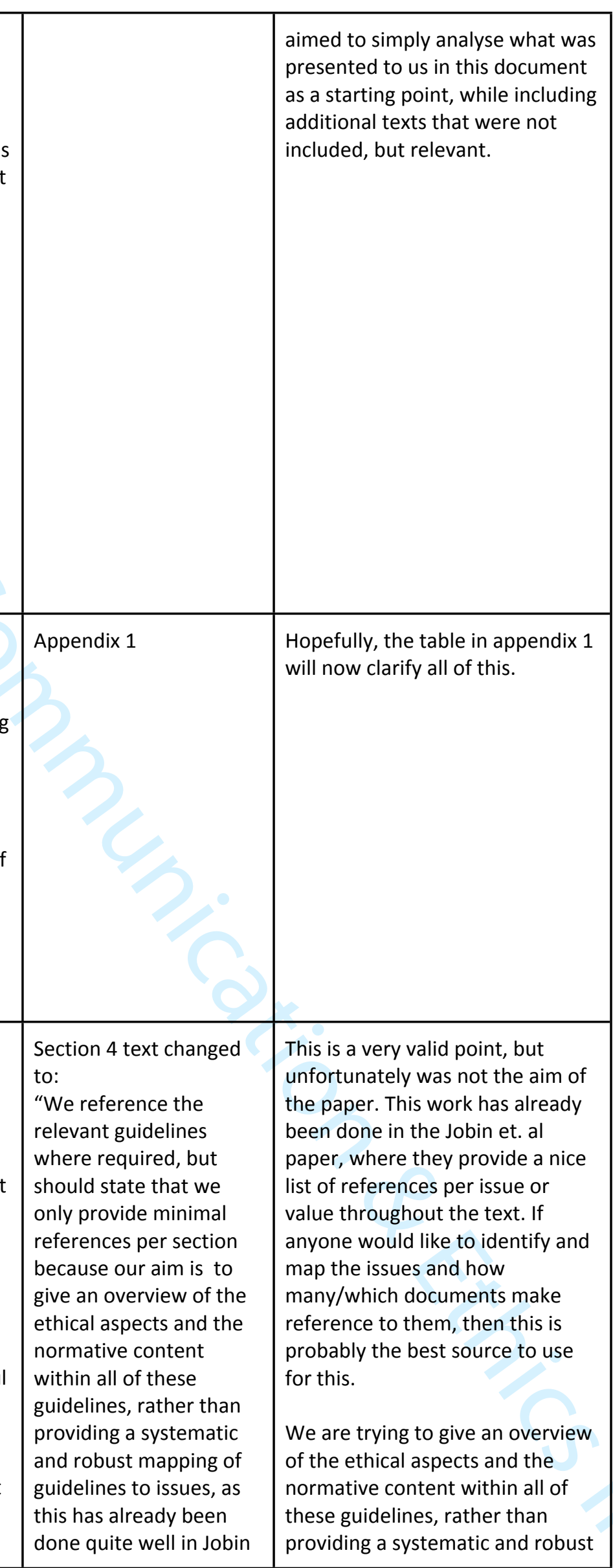


the overlapping guidelines would give readers an idea, not only of the fact that a prescription exist somewhere in any given guideline, but also of the fact that the same prescription is supported by multiple guidelines. Moreover, it would give the reader knowledge of what guidelines can be cited in support of any given point. It would be extremely valuable for the scientific community to have something like this, a real map of the practical prescriptions, and it could make this one of the most highly cited and most useful papers in Al ethics ever published. One way to provide the required information would be to group together in a table's cell all references to guidelines that are relevant to a single prescription (i.e. all the references that the authors seem to have wished to make in support of a given claim but couldn't, due to readability concerns) and to refer to such cell in the article's text, avoiding a cluttering of references. Such table could be included in the main article text, e.g. as an appendix at the end or, if space is too limited, as a downloadable attachment. Even if such solution is not practically feasible, I would still value a text that is harder to read but with comprehensive citations much higher, for its scientific and practical value, than a text involving only the key references (chosen how?). I really wish for the authors, the paper, and the journal, that a solution could be found to allow the authors to list all the citations they consider to be pertinent in support of any given prescriptive content item.

5) There are either missing citations, or wrong citations, or both. The following is a list of citations found in the text but not in the references:

O’Neil 2016 (twice)

Gilburt 2019

Demiaux 2017

Dawson et al 2019 (twice)

IBM 2017 (only IBM 2018 is cited) et. al (2019)."

mapping of guidelines to issues, as this has already been done quite well in Jobin et. al.

However, we agree that the text you mention in Section 4 is a poor reason for not listing all of the references, so this has now been changed.
Now included in references:

O’Neil reference

Gilburt reference

Demiaux \& Abdallah 2017

Dawson et. al

Koski \& Husso reference is now included

The IBM citations were two 
ICO 2018 (only ICO 2017 is cited)

Koski \& Husso 2018

$\mathrm{N}: \mathrm{B}$ : In some cases (IBM 2017 and ICO 2018), the missing citation is a work with the same title as a citation in the reference list, but with a different year. In these cases, it is not clear if this is an instance of a missing citation (there were two guidelines from the same author with different years, but only one was cited in references) or an instance of the author's inability to properly and consistently cite their references (or to property double - check their text). separate guidelines, which are now included in the reference.

The ICO guideline was from 2017, the 2018 reference was a typo/mistake, which has now been amended

Overall, we went through the entire document and corrected additional references that were incorrect or excluded. We are not sure what went wrong during the process, but the references and citations are now correct. 